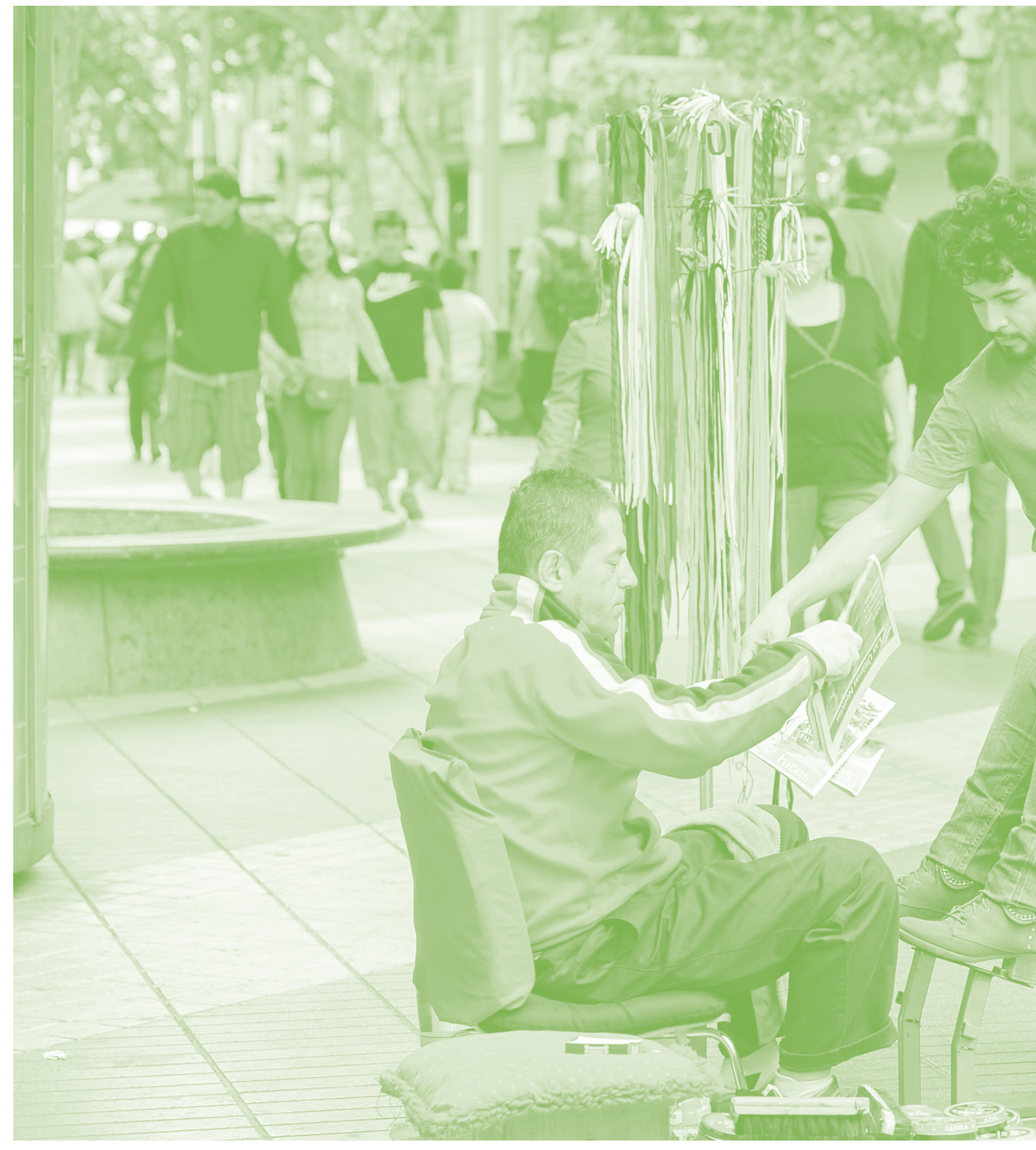



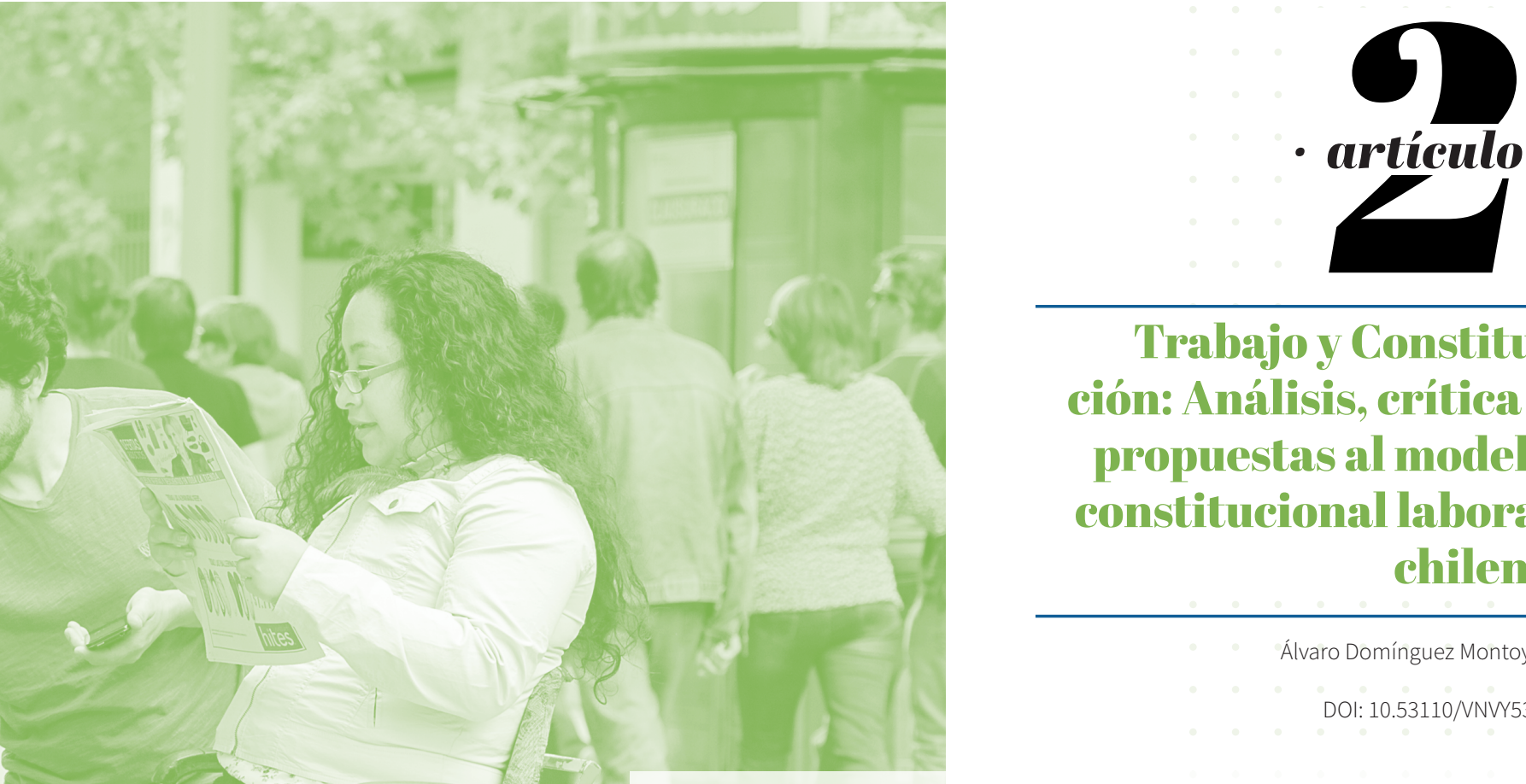

- artículo.

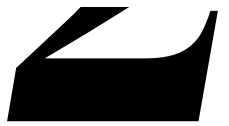

\section{Trabajo y Constitu- ción: Análisis, crítica y propuestas al modelo constitucional laboral chileno}

Álvaro Domínguez Montoya ${ }^{49}$

\section{A. El conflicto social y el derecho del trabajo}

El conflicto y cambio son aspectos inseparables de las relaciones industriales ${ }^{50}$ en atención a que son consecuencias de nuestro modelo de sociedad. ${ }^{51}$ Sus actores pertenecen a clases con intereses y expectativas diferenciadas, ${ }^{52}$ donde los trabajadores se encuentran en una posición dialéctica de contrapoder respecto de los empleadores, en que la defensa de sus objetivos no se basa en fórmulas de composición de intereses o de colaboración, sino de autodefensa. ${ }^{53}$

En este contexto, los modelos de relaciones colectivas de trabajo se inclinan por la aceptación y canalización del conflicto, mediante instrumentos y mecanismos que permiten su desarrollo adecuado. Por lo mismo, en sociedades de organización política democrática se impone un modelo de "pluralismo conflictual", que lo reconoce como una

\footnotetext{
${ }^{49}$ Abogado. Licenciado en Ciencias Jurídicas y Sociales. Universidad de Concepción. Máster en Drets Sociolaborals y Doctor en Derecho por la Universitat Autónoma de Barcelona. Profesor de Derecho del Trabajo, Facultad de Ciencias Jurídicas y Sociales, Universidad de Concepción. Casilla electrónica adominguez@udec.cl

${ }^{50}$ Hymman, 1981, p. 38.

51 Kahn-Freund, 1987, p. 65.

52 Ibíd., p. 112.

53 Baylos, 2009, p. 11.
} 
característica esencial de la misma y lo considera como un valor positivo, institucionalizándolo como medio de integración y de progreso del sistema social, en base a ciertas condiciones y definición de criterios razonables. ${ }^{54}$

En este escenario, la Libertad Sindical tiene un rol central, por cuanto implica no tan sólo el reconocimiento del conflicto en las relaciones de trabajo, sino también la importancia del diálogo social y la necesidad de afinidad entre los diversos intereses sociales. En cualquier sistema de derecho colectivo, su conformación recae en la contraposición de las expectativas de empresarios y trabajadores, como también, en las soluciones para resolverlos, ya sea mediante mecanismos institucionales, o bien, derivados de la propia autonomía colectiva, conciliando modelos basados en la heterocomposición y autocomposición.

Sin embargo, la legislación laboral, en general, reconoce y privilegia los mecanismos autocompositivos, empoderando a la parte débil mediante la actuación colectiva, dotándola de autotutela, como es el reconocimiento de la negociación colectiva como instancia de diálogo y la huelga como mecanismos de solución de los conflictos..$^{55}$

Frente a lo anterior, la pregunta es si nuestra Constitución Política de la República fija un marco político de convivencia democrática ante la contradicción de intereses en las relaciones de trabajo mediante el reconocimiento de la Libertad Sindical en sus dimensiones orgánica y funcional.

B. Como indica ROJAS, el principio universal de la Libertad Sindical acoge como derechos fundamentales los de Sindicación, de Negociación Colectiva y de Huelga, existiendo un acuerdo internacional de que la vigencia de estos derechos constituye una exigencia de los sistemas de gobiernos democráticos y pluralistas. ${ }^{56}$

En este contexto, lo correspondiente es observar en qué medida se reconocen estos derechos colectivos en nuestro modelo constitucional, y determinar sus límites y alcances en vistas de un sistema de valores y consensos políticos. Esto es de suma relevancia por cuanto en nuestro país la estructura de las relaciones de trabajo en su variante colectiva se encuentra limitada por el modelo ideológico de relaciones laborales que la dictadura cívico militar impuso hacia fines de la década del setenta y que se ha mantenido en las reformas de los gobiernos de transición democrática.

\footnotetext{
54 Gamonal, 2011, p. 57.

55 Caballero, 2018, p. 59.

56 Rojas, 2017.
} 
Esta cuestión influye decisivamente en las propuestas reguladoras de los modelos de relaciones colectivas de trabajo a nivel político y legal. Chile es un buen ejemplo a propósito de la normatividad impuesta durante el régimen militar de la época y que conocemos comúnmente como Plan Laboral, ${ }^{57}$ que tuvo como objeto el limitar el poder sindical y la manifestación de la autonomía colectiva en sus diversas dimensiones. ${ }^{58}$

El Derecho de Sindicalización se encuentra consagrado en el artículo 19 número 19 de la Constitución Política de la República, reconduciendo su regulación al legislador en lo relativo a sus condiciones de ejercicio y requisitos. En este contexto se subordina la autonomía de las organizaciones a la ley, resguardando que la afiliación sindical siempre sea voluntaria.

La Constitución señala que las organizaciones sindicales gozarán de personalidad jurídica por el solo hecho de registrar sus estatutos y actas constitutivas en la forma y condiciones que determine la ley.

En una primera lectura, se observa una concepción restringida e incompleta de este derecho, por cuanto no se contienen sus elementos esenciales, sin perjuicio de que la regulación legal de los requisitos y forma de la afiliación, los niveles de organización y la estructura de funcionamiento se encuentra regulada en el Código del Trabajo. Esta formula no dialoga con la noción amplia de la Libertad Sindical contenida en el Convenio 87 sobre la Libertad Sindical y la protección del Derecho de Sindicación de la Organización Internacional del Trabajo. ${ }^{59}$

De la misma forma, el texto constitucional al someter el desarrollo de este derecho fundamental a la ley, entrega la eficacia del derecho a un modelo normativo que no garantiza efectivamente los elementos instrumentales para la gestión de la actividad sindical reconocidos en el Convenio $135^{60}$ y Recomendación $143^{61}$ sobre los representantes de los trabajadores

\footnotetext{
57 Para una mayor profundización sobre el punto ver: Irureta, 2009; Caamaño, 2008; Rojas, 2007.

${ }^{58}$ Rojas, 2007, pp. 202 y ss.

${ }^{59}$ Convenio 87 sobre la Libertad Sindical y la protección del Derecho de Sindicación de la Organización Internacional del Trabajo, adoptado en San Francisco, $31^{a}$ reunión CIT (09 julio 1948), entrando en vigor el 4 de julio de 1950, ratificado por Chile el 1 de febrero de 1999.

${ }^{60}$ Convenio 135 Convenio sobre los representantes de los trabajadores, adoptado en Ginebra, 56 ra reunión CIT (23 junio 1971), ratificado por Chile el 13 de septiembre de 1999 .

${ }^{61}$ Recomendación sobre los representantes de los trabajadores, adoptado en Ginebra, 56 reunión CIT (23 junio 1971).
}

C.

El Derecho a Sin-
dicalización:
entre restric-
ciones y exclu-
siones de partici-
pación política


de la Organización Internacional del Trabajo. ${ }^{62}$

Por ejemplo, respecto del crédito horario, ${ }^{63}$ a nivel legislativo se limita su tiempo y remuneración, ${ }^{64}$ lo que impide, en términos prácticos, que los representantes de los trabajadores en la empresa gocen de protección eficaz en su actividad sindical, no disponiendo de facilidades apropiadas que permitan una compatibilidad efectiva de sus funciones de representación con su trabajo.

La misma situación ocurre respecto del Derecho de Información, donde si bien han existido avances en la materia, sustantivamente se mantiene un modelo tasado y circunscrito a cuestiones económicas y financieras dentro del contexto de negociación colectiva, excluyendo otras materias de interés para el ejercicio de las funciones sindicales y representación de intereses laborales.

Similar escenario ocurre respecto del Derecho de Consulta, el que no encuentra desarrollo ni cabida en nuestro modelo sindical para el ejercicio de las funciones de representación laboral.

Como corolario de lo anterior, en la Constitución actual se establece una prohibición y limitación de las organizaciones sindicales de intervenir en actividades partidistas, ${ }^{65}$ fijando incompatibilidades de cargo de directores superiores de organizaciones gremiales con cargos políticos ${ }^{66}$ y para ser candidatos a diputados o senadores, proscribiendo la actividad sindical de la política institucional.

D. En general, la Negociación Colectiva regulada en el artículo $19 \mathrm{~N}^{\circ} 16$ de la Constitución Política, es estudiada desde dos perspectivas: como un pro-

El Derecho a la Negociación Colectiva:fragmentos $y$ limitaciones de sujetos y niveles

\footnotetext{
${ }^{62}$ Esto último sin perjuicio de una lectura explicita e interpretativa a la luz de tratados internacionales sobre la materia. Al respecto Vid. Rojas, 2017, pp. 20 y 21.

${ }^{63}$ Materia regulada en el artículo 249 del Código del Trabajo.

${ }^{64}$ Las "horas sindicales" no podrán ser inferiores a seis horas semanales por cada director, ni a ocho tratándose de directores de organizaciones sindicales con 250 o más trabajadores, pudiendo acumularse y distribuirse entre éstos. No obstante, la remuneración será de cargo del sindicato respectivo y el pago de las remuneraciones, beneficios y cotizaciones previsionales de cargo del empleador que puedan corresponder a aquéllos durante el tiempo de permiso.

${ }^{65}$ Artículo 19 N 19 de la Constitución Política de la República de Chile.

${ }^{66}$ Artículo 23 inciso $1^{\circ}$, frase 2 de la Constitución Política de la República de Chile.

${ }^{67}$ Artículo 57 Nº 7 de la Constitución Política.
} 
cedimiento, o bien como un derecho fundamental. ${ }^{68}$

En un primer punto de vista, es un procedimiento mediante el cual uno o más empleadores, con uno o más sindicatos, acuerdan condiciones comunes de trabajo y remuneraciones, por un tiempo determinado mediante un instrumento colectivo. ${ }^{69}$

Desde un segundo punto de vista, la Negociación Colectiva puede ser enfocada desde la perspectiva de un derecho fundamental, ya sea como parte como parte del derecho a la libertad de trabajo y su protección ${ }^{70} 0$ bien desde la perspectiva de la Libertad Sindical. ${ }^{71}$

En un contexto general, este derecho fundamental cumple con una triple función: como medio de solución de conflictos; instrumentos de gobierno del sistema de relaciones laborales en su conjunto y fuente de creación de normas laborales. ${ }^{72}$ En este esquema, la negociación colectiva persigue armonizar los intereses contradictorios de los actores laborales, para que, de común acuerdo y con plena autonomía, fijen los salarios y condiciones de trabajo en conformidad a los procedimientos que establece la ley. ${ }^{73}$

En cuanto a su contenido, sin perjuicio de sus distintas interpretaciones, ${ }^{74}$ se observa de su texto expreso que ésta se encuentra limitada en su titularidad y cobertura a un derecho de los trabajadores en el ámbito de la empresa.

En la misma línea, la Constitución remite a la ley las modalidades de la Negociación Colectiva y los procedimientos adecuados para lograr en ella una solución justa y pacífica. De igual manera, remite al legislador la definición de los casos en que la negociación colectiva deba someterse a arbitraje obligatorio, el que corresponderá a tribunales especiales de expertos. A partir de esta regulación, dos son los principales problemas del alcance de

\footnotetext{
${ }^{68}$ Caballero, 2018, p. 58.

${ }^{69}$ No obstante el Tribunal Constitucional resolvió que la negociación colectiva es el derecho de cada trabajador de manifestarse de forma grupal para la consecución de un interés colectivo consistente en negociar con su empleador condiciones de trabajo, entre ellas la más importante, la retribución por su trabajo, de manera tal que no radica exclusivamente en los sindicatos la titularidad de la misma, pudiendo por tanto asumir la titularidad de la misma otras formas de organización sindical, como los grupos negociadores o coaliciones transitorias. Vid. Sentencia Tribunal Constitucional N³016(3026)-16-CPT, 9 de mayo de 2016

70 Lizama, 2017, p. 62.

${ }^{71}$ Caballero, 2018, p. 58.

72 Gamonal, 2011, p. 213.

${ }^{73}$ Caamaño y Ugarte, 2008, p. 32.

${ }^{74}$ Sobre el punto hemos seguido la síntesis constitucional realizada por Rojas, 2017, pp. 21 y ss.
} 
este derecho: la titularidad del derecho y los niveles de negociación.

Respecto de la titularidad, el debate se centra en dos polos: por una parte, en si el derecho a negociar colectivamente corresponde exclusivamente al sindicato, o bien, por otra, si este es un derecho individual que se ejerce de forma colectiva a través de las distintas formas de organización que asuman los trabajadores, ya sea mediante el sindicato o los grupos negociadores.

Este debate se produce por cuanto el Tribunal Constitucional ${ }^{75}$ resolvió que el derecho a negociar colectivamente corresponde a todos y cada uno de los trabajadores. En otros términos, la activación o determinación originaria para ejercerlo o no, reside en los trabajadores individualmente considerados, aunque se ejerza de forma colectiva. En consecuencia, concluyó que la agrupación voluntaria de trabajadores para efectos de negociar colectivamente era una manifestación del derecho de asociación y por lo mismo la titularidad para negociar colectivamente no puede ser única, exclusiva y excluyente de los Sindicatos, por cuanto tales representan una sola forma de organización de los trabajadores.

A partir de lo anterior ha existido un intenso debate administrativo ${ }^{76}$ y doctrinario respecto al alcance y titularidad de este derecho, ${ }^{77}$ lo que mantiene en buena parte los vicios de fragmentación sindical y paralelismo heredados de la dictadura, que pese a lecturas progresistas integradas con tratados internacionales, reconoce de modo fragmentario e incompleto las manifestaciones del derecho a negociar colectivamente, en el que finalmente entregan su reconocimiento a la intervención de los tribunales de justicia, con las incertidumbres que lo anterior conlleva.

E. En nuestro ordenamiento jurídico no existe una definición legal de huelga, siendo su conceptualización realizada por la doctrina y jurisprudencia.

En este contexto, la Constitución chilena consagra el derecho fundamental de la libertad sindical, pero no establece en forma expresa el derecho de huelga. Es más, se indica en el artículo 19 № 16 inciso final, que no podrán declararse en huelga los funcionarios del Estado ni de las municipalidades. Tampoco podrán hacerlo las personas que trabajen en corporaciones o empresas, cualquiera sea su naturaleza, finalidad o función,

\footnotetext{
75 Sentencia del Tribunal Constitucional N³016(3026)-16-CPT, 9 de mayo de 2016.

${ }^{76}$ Al respecto el Dictamen de la Dirección del Trabajo ORD N¹163/29 y ORD. No3938/33 de fecha 27 de julio de 2018.

${ }^{77}$ Entre otros: Irureta, 2016, pp. 13-37; Ugarte, 2017; Aylwin, 2017, p. 31.
} 
que atiendan servicios de utilidad pública o cuya paralización cause grave daño a la salud, a la economía del país, al abastecimiento de la población o a la seguridad nacional. En este marco, se encarga a la ley el establecer los procedimientos para determinar las corporaciones o empresas cuyos trabajadores estarán sometidos a la prohibición que establece este inciso, lo que da a lugar distintas interpretaciones sobre su configuración, modalidades de ejercicio y extensión.

En este escenario, debido a que el tenor literal del precepto constitucional prohíbe la huelga en determinados supuestos, ¿cuál es el fundamento de su configuración como derecho? Como resume ROJAS, dos son las tesis enmarcadas en la problematización del reconocimiento expreso o implícito. ${ }^{78}$ Por una parte, al entenderse que respecto de determinados supuestos está prohibida, a contrario sensu, corresponde entender que los demás trabajadores no incluidos en tal prohibición tienen el derecho a declarar y hacer efectiva la huelga. ${ }^{79}$ Por otro lado, se plantea que el derecho a huelga se reconoce expresamente a partir de la idea de la autonomía sindical, en cuanto comprende todos los elementos de la libertad sindical. ${ }^{80}$ Una última tesis reconoce la huelga, pero a partir de la idea del bloque de constitucionalidad, integrado por el Pacto de Derechos Económicos Sociales y Culturales, como también, los convenios de la Organización Internacional del Trabajo. ${ }^{81}$

Fuera cual sea la tesis sostenida, en todos los casos se reconoce como derecho fundamental. ${ }^{82}$

Por su parte, también la jurisprudencia administrativa ${ }^{83}$ y judicial ${ }^{84}$ ha entendido la configuración de la huelga en nuestro ordenamiento jurídico

\footnotetext{
78 Rojas, 2017, p. 22. En similar sentido ver Gamonal, 2014, pp. 116 y ss.

${ }^{79}$ Macchiavelo, 1986, p. 443; Irureta, 2006, p. 187; Caamaño y Ugarte, 2008, p. 78.

80 Gamonal, 2014, p. 121.

81 Tapia, 2012.

82 Op. Cit., Irureta, 2006, p. 188; Caamaño y Ugarte, 2008, p. 79; Gamonal, 2014, pp. 112 y ss.; Ugarte, 2016, pp. 91-101; Tapia, 2012, pp. 160-167; Varas, 2014, pp. 63 y ss.; Leyton, 2017, pp. 781-804.

83 Dictamen de la Dirección del Trabajo N5346/92 de 28 de octubre de 201; Nº 441/7 de 25 de enero de 2017; N448/6 de 24 de enero de 2018.

${ }^{84}$ Corte de Apelaciones de Santiago, rol 142-2014, 11 de marzo de 2014; Corte Suprema, rol 3.514-2.014, 4 de diciembre de 2014; Corte Suprema, rol 10.4442014, 29 de enero de 2015; Corte de Apelaciones de Rancagua, rol №159-2011, 5 de enero de 2012; Corte de Apelaciones de San Miguel, Rol 183-2014, Reforma Laboral, 9 de julio de 2014; Corte de Apelaciones de Santiago, Rol 1144 - 2015, Reforma Laboral, 23 de octubre de 2015; Corte de Apelaciones de Antofagasta, Rol 91 - 2015, Reforma Laboral, 24 de septiembre de 2015; Corte de Apelaciones de Copiapó, rol 154-2018, 5 de noviembre de 2018, entre otras. ${ }^{85}$ Vid. Corte Suprema, rol 3514-2014, 4 de diciembre de 2014; y Corte Suprema,
} 
como expresión de la libertad sindical y derecho fundamental, desde la formulación tácita en nuestra Constitución a partir de una lectura integrada con los tratados internacionales vigentes en Chile. ${ }^{85}$

A nivel legal, el Código del Trabajo regula el ejercicio de la huelga en el marco de la negociación colectiva reglada en el Libro IV, Título IV, Capítulo VI, en los artículos 345 al 363, sin perjuicio de otras normas de tutela de ésta.

Pese a lo anterior, nuevamente aparecen limitaciones de orden constitucional que, al final del día, entregan la eficacia y reconocimiento de este derecho a un contexto de debilidad sindical y su tutela de los tribunales de justicia.

F. Si tratamos de ver cuál es la regulación de las distintas dimensiones de la

La Libertad Sindical y los funcionarios públicos: la negación de los derechos colectivos libertad sindical de los funcionarios públicos podemos señalar, en general, que nuestra Constitución y legislación laboral prohíbe y niega el ejercicio de los derechos colectivos, por cuanto excluye a los trabajadores y trabajadoras del sector público de sus normas.

En efecto, la Constitución al entregar la regulación de los derechos de la libertad sindical a la ley, no asegura el efectivo derecho y desarrollo de éstos. En este esquema, las leyes $18.834^{86}$ y $18.833^{87}$ prohíben expresamente a los Funcionarios Públicos Municipales y de la Administración del Estado, organizar o pertenecer a sindicatos en el ámbito de la administración del Estado. Así también, dirigir, promover o participar en huelgas, interrupción o paralización de actividades, totales o parciales, en la retención indebida de personas o bienes, y en otros actos que perturben el normal funcionamiento de los órganos del Estado.

Es más, la huelga se prohíbe expresamente para los funcionarios del Estado y Municipales, según se desprende del artículo $19 \mathrm{~N}^{\circ} 16$ inciso final de la Constitución Política de la República. Lo anterior se ve reforzado por sanciones penales ante toda interrupción o suspensión colectiva, paro o huelga de los servicios públicos o de utilidad pública o en las actividades de la producción, del transporte o del comercio y que produzcan alteraciones del orden público o perturbaciones en los servicios de utilidad pública o de funcionamiento legal obligatorio o daño a cualquiera de las industrias vitales, constituyendo tales actividades delito, siendo castigados con presidio o relegación menores en sus grados mínimo a medio. ${ }^{88}$

\footnotetext{
36 Artículo 84 letra i).

87 Artículo 84 letra i).

${ }^{88}$ Artículo 11 de la ley 12.927 sobre Seguridad del Estado.
} 
No obstante, y como reconoce VARAS, pese a las claras prohibiciones, la realidad sindical ha desbordado estas limitaciones. En nuestro país, el sector público realiza numerosas negociaciones informales fruto de las cuales se firman diversos tipos de acuerdos, constitutivos de instrumentos colectivos atípicos. Incluso los funcionarios recurren al ejercicio del derecho de Huelga, por medio de la realización de movilizaciones y paralizaciones, para de esa forma equiparar su poder negociador ante la autoridad. ${ }^{89}$ Por lo mismo, en los hechos, las Asociaciones de Funcionarios Públicos negocian colectivamente y ejercen el derecho a huelga, incluso con menos obstáculos y regulaciones que los trabajadores del sector privado. ${ }^{90}$

Lo anterior demuestra la necesidad de regular el derecho sindical armónicamente y de conformidad al Convenio 151 de la Organización Internacional del Trabajo, ${ }^{91}$ y adecuarlo a la realidad de nuestro país, reconociendo formalmente los diversos atributos de la Libertad Sindical en todas sus dimensiones.

En el debate actual por una nueva Constitución hemos iniciado el camino para su proceso de cambio. La pregunta es cómo definimos nuestro modelo político en sus distintas dimensiones y cuál es nuestro modelo de relaciones laborales colectivas que queremos.

En este esquema su discusión es importante, no tan sólo por cómo asumimos y otorgamos centralidad al trabajo socialmente, sino también, porque determina las estructuras sociales y las formas de equilibrar la relación de poder entre trabajadores y empleadores, lo que adquiere relevancia en un modelo que se caracteriza por su excesivo intervencionismo y su transgresión del principio de Libertad Sindical, entendido en su aceptación amplia y democrática. Pero ¿cuál es el modelo que queremos? ¿Cuáles son las propuestas?

Creemos que su orientación primaria debe ir en la línea de consagrar una modelación desformalizada que otorgue centralidad política a la autonomía colectiva ante el conflicto social de trabajo y propiedad.

A nivel orgánico, debe consagrarse en términos igualitarios el derecho a sindicalización en el sector público y privado, en el que la constitución de sindicatos sea al nivel que autónomamente fijen los trabajadores, de-

Varas, 2017, p. 88

90 Ibíd.

${ }^{91}$ Convenio 151 sobre las relaciones de trabajo en la administración pública, adoptado en Ginebra, 64 reunión CIT (27 junio 1978), ratificado por Chile el 17 de julio de 2000. 
terminando a su vez los niveles de representación. En ese esquema, debe mantenerse la voluntariedad de la afiliación en cualquier nivel, ya sea para afiliarse como desafiliarse de un sindicato, eliminando las inhabilidades políticas y reconociendo facilidades y garantías instrumentales para el ejercicio de la función sindical, mediante derechos de información, consulta y crédito horario.

En su perspectiva funcional, la negociación colectiva debe tratarse de un derecho de ejercicio colectivo cuya titularidad recae en los trabajadores organizados en sindicatos, pudiendo negociar las organizaciones transitorias de trabajadores sólo si en la empresa no existen organizaciones sindicales, con la finalidad de evitar el paralelismo laboral.

En esta línea, serán las organizaciones sindicales en sus distintos niveles de representación los que definan y ejerzan el derecho de negociar colectivamente al nivel que estimen conveniente, pudiendo ser nacional, ramal o de empresa, según la representación que tengan en esos niveles, siendo competencia del legislador la definición de los mecanismos escalonados o graduados de extensión.

Respecto de la huelga, una alternativa es el reconocimiento de su titularidad universal, siendo un derecho de los trabajadores del sector privado y público, excluyendo a las Fuerzas Armadas, la policía y el Poder Judicial. En esto, las organizaciones sindicales tendrán autonomía para definir cuáles serán los intereses laborales que se defenderán a través del ejercicio del derecho a huelga, en el que el legislador no podrá restringir su ámbito de aplicación ni su contenido esencial, siendo su único límite aquellos casos en que se afecte la vida, la salud o la seguridad de la población. 
Aylwin, A. (2017)

¿Puede negociar colectivamente los grupos de trabajadores en el Código del Trabajo modificado por la ley 20.940?', en Tapia, F., Negociación Colectiva: Estudios en homenaje al profesor Emilio Morgado Valenzuela. Santiago: Sociedad chilena de Derecho del Trabajo y la Seguridad Social.

Baylos, A. (2009)

Sindicalismo y Derecho Sindical. Albacete: Bomarzo.

Caamaño, E. (2008)

'Las materias objeto de negociación colectiva y la libertad sindical: el fantasma de los "Chicago Boys" a 30 años del plan laboral', Estudios Laborales, 3:117-136.

Caamaño, E. y Ugarte, J. (2008)

Negociación Colectiva y Libertad Sindical. Un enfoque crítico. Santiago: Legal Publishing.

Caballero, R. (2018)

Derecho Colectivo del Trabajo. Santiago: DER.

Gamonal, S. (2011)

Derecho Colectivo del Trabajo. Santiago: Legal Publiishing.

Gamonal, S. (2014)

'El derecho de Huelga en la Constitución chilena', Revista de derecho (Coquimbo), 20(1).

Hymman, R. (1981)

Relaciones industriales: una introducción marxista. Madrid: Blume.

Irureta, P. (2006)

Constitución y Orden Público Laboral. Un análisis del art. 19 No 16 de la Constitución chilena. Santiago: Universidad Alberto Hurtado.

Irureta, P. (2009)

'Regulación de la Libertad Sindical entre 1973-1990', en Lira, E. y Rojas, H., Libertad Sindical y Derechos Humanos. Análisis de los Informes del Comité de Libertad Sindical de la OIT (1973-1990). Santiago: LOM.

Irureta, P. (2016)

'El instrumento colectivo en la reforma laboral de 2016', Revista chilena de derecho del trabajo y de la seguridad social, 7(14). 
Kahn-Freund, O. (1987)

Trabajo y Derecho. Madrid: Ministerio de Trabajo y Seguridad Social.

Leyton, J. (2017)

'El derecho a la huelga como un derecho humano fundamental: reconocimiento y limitaciones en el Derecho Internacional', Revista Chilena de Derecho, 44(3).

Lizama, L. (2017)

La reforma laboral explicada y comentada. Santiago: Luis Lizama Portal \& CIA abogados. Disponible en: http://lizamabogados.cl/wp-content/uploads/2019/07/Libro-Reforma-Laboral-versi\%C3\%B3n-Web. pdf (Consulta: 17 agosto 2021).

Macchiavelo, G. (1986)

Derecho Colectivo del Trabajo. Santiago: FCU.

Rojas, I. (2007)

'Las reformas laborales al modelo normativo de negociación colectiva del plan laboral', Revista lus et Praxis, 13(2):195-221.

Rojas, I. (2017)

'Los derechos de libertad sindical en la Constitución chilena', Revista de Derecho de Valdivia.

Tapia, F. (2012)

'El Reconocimiento Constitucional de la Libertad Sindical y el Derecho de Negociación Colectiva', en Gobierno de Chile, Negociación Colectiva en Chile: la Debilidad de un Derecho Imprescindible. Santiago: Dirección del Trabajo.

Ugarte, J. (2016)

Huelga y Derecho. Santiago: Thomson Reuters.

Ugarte, J. (2017)

'Negociacion colectiva, huelga y reforma: una nueva cartografía', en Universidad Diego Portales, Anuario de Derecho Público. Santiago: UDP.

Varas, K. (2014)

'La huelga, un derecho fundamental', en Universidad Diego Portales, Informe Anual sobre Derechos Humanos en Chile. Santago: UDP.

Varas, K. (2017)

'El derecho a negociación colectiva en la administración del Estado', en Yañez, S. y Rojas, I., Empleo Público en Chile: ¿trabajo decente en el estado? apuntes para el debate. Santiago: FLACSO. 
